\title{
ON THE PATHOGENESIS OF HEADACHE FOLLOWING TIA
}

\author{
CHARLES ANDRÉ* MAURICE B. VINCENT**
}

\begin{abstract}
Twelve out of 49 patients with single or multiple transient ischemic attacks (TIAs) had TIArelated headaches, mostly in close temporal relation to the ischemic onset. Headache predominated in patients taking vasodilators when TIA occurred or with orthostatic hypotension at the first clinical examination, but arterial hypertension or a personal history of migraine were not more frequent in patients with headache. The site of the pain did not correlate with the presumed territory of cerebral ischemia. Pain during TIA is conceivably due to an interaction between cerebral vessels and the surrounding nervous system. Blood vessels have a sturdy physiological role corcerning blood flow regulation, with receptors and signaling molecules potentialy involved with pain production. Reflex mechanisms should justify pain in other areas.
\end{abstract}

KEY WORDS: transient cerebral ischemia, cortisol, headache, neuroendocrine system, serotonin, trigeminovascular system.

\section{A respeito da fisiopatologia da cefaléia pós-ataque isquêmico transitório}

RESUMO - Em uma série de 49 pacientes com episódios únicos ou múltiplos de ataque isquêmico transitório (AIT), 12 apresentaram cefaléia em estreita associação com as manifestações isquêmicas. Cefaléia foi mais frequente em pacientes com hipotensão ortostática ao primeiro exame pós-TIA e naqueles em uso de vasodilatadores. Não foi detectada associação com hipotensão arterial ou com história pessoal ou familial de enxaqueca. A localização da dor teve pouca correlação com o território isquêmico, em pacientes com AIT vertebrobasilar ou carotídeo. A dor durante os AITs se deve provavelmente a interação entre vasos sanguíneos e sua inervação. Os vasos têm papel central no controle do fluxo sanguíneo cerebral. A gênese da dor é provavelmente ligada à estimulação de receptores e liberação de moléculas sinalizadoras da agressão isquêmica. Mecanismos reflexos parecem justificar a dor em territórios distantes à isquemia.

PALAVRAS-CHAVE: cefaléia, cortisol, isquemia cerebral transitória, serotonina, sistema neuroendócrino, sistema trigeminovascular.

Headaches are common in cerebrovascular disorders, particularly in intracranial haemorrhages, where head pain may be very pronounced. Headaches may also occur in ischaemic strokes, including transient ischaemic attacks (TIAs) ${ }^{7.20 .21}$. A previous study showed that the frequency of headaches in single and multiple TIAs are similar and that the site of the pain poorly correlates with the ischaemic territory. The time course of the headache did not necessarily correspond to that of other symptoms. Patients with postural hypotension or taking vasodilators tended to suffer more headache attacks ${ }^{2}$. The literature on TIA-related headache seems to be scarce and the available information confusing, which persuaded us to further spcculate on its putative pathogenesis.

Firstly, we consider it important that whatever ischaemia do to vessels and the surrounding nervous tissue the process is reversible. Pain should therefore not be related to any structural

Serviço de Neurologia, Hospital Universitário Clementino Fraga Filho, Universidade Federal do Rio de Janeiro (UFRJ), Brasil: *Professor Assistente, **:Professor Adjunto. Aceite: 18-novembro-1996. 
permanent lesion. It is therefore dynamic, chemically mediated. Secondly, pain should be evoked by events closely related to the arterial bed. Vessels do have muscles, neurons and an active interacting endothelium that produces several signaling molecules due to activation of a series of receptors. Thirdly, pain activation has to occur not exclusively at the site of injury but also in distant areas. Two possibilities could be considered in this respect. Either the headache would spread through the nerve fibres network within the vessels' wall or the blood itself would carry pain-generating substances released during the ischaemic process. It is the objective of the present work to revicw such possibilities based on our experience on TIA-induced headaches.

\section{PATIENTS AND METHODS}

A comprehensive description of our population is described elsewhere ${ }^{2}$. Basically, we studied 49 patients ( 30 males and 19 females) who presented with focal neurological deficits spontaneously recovering within up to 24 hours, fulfilling the criteria for Transient Ischaemic Attacks (TIAs). The carotid and vertebrobasilar territorics were affected in respectively $33(67 \%)$ and $15(31 \%)$ cases. Onc patient (2\%) had different episodes in both arterial systems. Twenty-seven patients (55\%) had multiple attacks, whereas $22(45 \%)$ had a unique episode. Four patients were under acetylsalicylic acid and 13 were taking vasodilators. No patient fulfilled the International Headache Society criteria for Migraine ${ }^{14}$. Arterial hypertension was verified in 31 cases. A CT scan was performed in 42 patients and duplex-scan examinations in 38 . The diagnosis of headache related to TIA followed the criteria of the IHS (code 6.1 .1$)^{14}$. Heaclache se verity was assessed by an analogue visual rating scale (VAS). We now describe in more detail our findings in patients exhibiting multiple episodes of TIA-related headache.

\section{RESULTS}

Table 1 shows the main features of the 12 patients (24\%) who had TIA-related headache ${ }^{2}$. It is noteworthy that the pain onset was related to the onset of the ischaemic symptoms in the majority of the cases. In cases where headache preceded the ischaemic symptoms, this interval never exceeded 30 minutes. The headaches were predominantly throbbing, mild to moderate, and could last from only 10 minutes to as much as 12 hours. Pain could predominate in an anterior or posterior distribution, and was frequently diffuse or bilateral even in patients with carotid circulation attacks. Two additional patients with carotid artcry attacks experienced pain contralateral to the ischaemic focus. On the other hand, two out of five patients with vertebrobasilar attacks experienced unilateral headache.

Age, arterial hypertension and the number of attacks did not influence the frequency of headache. Hendaches occurred similarly in patients with single (5 of 22 cases, $23 \%$ ) and multiple (7 of 27 cases, 26\%) TIAs. However, in 7 patients with headache and recurrent episodes of 'TIA the headaches were rather stereotyped (Table 2). These patients had headache in every TIA attack. The number of attacks varied from 2 to 10 . In all but one patient the headache persisted for a longer

Table I. Clinical aspects of headache in twelve TIA patients*.

\begin{tabular}{|c|c|c|c|c|}
\hline Onset $^{1}$ & Pre-TIA: 5 & With TIA: 5 & Post-TIA: 1 & Variable: I \\
\hline Localization ${ }^{2}$ & Bilat/median: 6 & Unilateral: 6 & & \\
\hline Duration? & 10 minutes to 12 hours & & & \\
\hline Severity ${ }^{4}$ & mild to moderate: 9 & & & \\
\hline Quality & Pulsating: 9 & Non-pulsating: 3 & & \\
\hline Volniting 5 & $5 \operatorname{cascs}(41.5 \%)$ & & & \\
\hline
\end{tabular}

*From André et il.?

'Pre-TIA: max. $30 \mathrm{~min}$. Per-T1A: headtache onset concomitant with other sings and symptoms. 'Unilateral headache in 2 of 5 patients with vertebrobusilar TI $\Lambda$; headache contralateral to the ischaemia in 2 patients with carotid lesions, ipsilateral in 2, bilaterat in 3. 'Headache duration similar to TIA duration in $33 \%$, greater in $33 \%$ und lesser in $33 \%$. $\quad+30 \%$ to $80 \%$ of pain assessed by a visual analogue scile. In 4 of 5 pitients witlı vertebrobasilar TIA 
Table 2. Clinical aspects of headache in seven patients with recurrent episodes of TIA ${ }^{\text {*1: }}$

\begin{tabular}{|c|c|c|c|c|c|c|c|c|}
\hline \multicolumn{2}{|c|}{ Patient } & \multicolumn{3}{|c|}{ TIA attacks } & \multicolumn{4}{|c|}{ Headache } \\
\hline Scx & Age & Duration & Number & Distribution & Duration & Quality & Severity & Localization \\
\hline fem. & 60 & $5-10 \mathrm{~min}$ & 5 & carotid & $\leq 12 \mathrm{~h}$ & pulsating & moderate & contralateral \\
\hline fem. & 61 & $5-10 \mathrm{~min}$ & 2 & carotid & $30 \mathrm{~min}$ & pulsating & moderate & diffusc \\
\hline fem. & 33 & $\leq \mathrm{lh}$ & 3 & carotid & $2 \mathrm{~h}$ & pulsating & moderate & bilateral \\
\hline fem. & 51 & $20-30 \mathrm{~min}$ & $>10$ & carotid & $1 \mathrm{~h}$ & pulsating & $\begin{array}{l}\text { moderate } \\
\text { / severe }\end{array}$ & ipsilateral \\
\hline male & 4.5 & $30 \mathrm{~min}$ & 8 & caroticl & $30-60 \mathrm{~min}$ & pulsatting & severe & diffuse \\
\hline male & 79 & $\leq 30 \mathrm{~min}$ & 5 & $\begin{array}{l}\text { vertebro } \\
\text { basilar }\end{array}$ & $90 \mathrm{~min}$ & pressing & moderate & $\begin{array}{l}\text { right } \\
\text { sidted }\end{array}$ \\
\hline male & 54 & $1-2 h$ & 4 & $\begin{array}{l}\text { vertebro } \\
\text { basilar }\end{array}$ & $20-30 \mathrm{~min}$ & pulsating & $\begin{array}{l}\text { moderate } \\
\text { / severe }\end{array}$ & $\begin{array}{l}\text { right } \\
\text { sided }\end{array}$ \\
\hline
\end{tabular}

* From André et al! :

period than any other symptom. The headache was pulsating, moderate to severe, lasting longer than the TIA itself except in one patient. Again, there was a weak correlation between the site of pain and the distribution of the ischaemia.

\section{DISCUSSION}

Docs TIA induce headache? Apparently yes. Although the frequency varies from 6 to $44 \%^{2.13 .20}$, the close onset relation indicates that the two phenomena are somehow connected.

Are the mechanisms of TIA-related headache clear? Apparently not: Why should the incidence vary that much? Why headache correlates weakly with the territory, severity and multitude of TIA attacks? Our clinical findings should be interpreted under the light of modern concepts of primary headaches pathophysiology, specially migraine, a condition that must be compared with TIA-induced headache (Table 3).

In our series patients with carotid disease frequently had bilateral or even contralateral pain and those with vertebrobasilar cpisodes often had a unilateral headache. In general, a weak correlation between the pain area and the TIA territory was observed.

As Ray and Wolff first described, pain referred to the ipsilateral fronto-ocular area may be elicited by stimulating the proximal segments of the middle and anterior cerebral arteries, whereas

Table 3. Important similarities and differences between headache following TIA and migraine.

\begin{tabular}{ll}
\hline \multicolumn{1}{c}{ Similarities } & Differences \\
\hline - Throbbing quality & - Older agc \\
- Nausea and vomiting & - No clear female predominance \\
- Constant association in patients with recurrent episodes? & - Frequent bilateral distribution \\
- Higher freguency in cortical TIA? & - No prodromic symptom \\
- Transient neurologic dysfunction as a trigger & - Shorter duration \\
& - Rarely onset follows other symptoms \\
\hline
\end{tabular}


the stimulation of infratentorial arteries elicits pain referred to the occiput or upper cervical areas ${ }^{27}$. In patients with ischaemic cerebrovascular disorders the headache may also vary according to the affected artery ${ }^{13.21}$, but the presence of bilateral or midline pain observed in ours as well as in previous studies ${ }^{2()}$ suggests that the mechanisms determining the pain site may be more complex.

Does the pain spread through nerves or blood? The first possibility is considered in the following.

Ischaemic conditions modify and stimulate tissues by a variety of biochemical phenomena. The pathophysiology of cerebral ischaemia is fraught with controversy, but at lcast some points seem to be important in this regard. Ischaemic penumbra is the brain tissue pertused at a level between the thresholds of functional impairment and of morphological integrity ${ }^{3}$. Although in TIA this phenomenon does not occur to the point of a permanent deficit, the ischaemic signals are undoubtfully triggered to some extent. There may be accumulation of lactate, NMDA receptormediated calcium influx to the cells, release of excitatory aminoacids and other molecules such as nitric oxide(NO), nerve growth factor, brain derived neurothrophic factor and basic fibroblast growth factor. Headache could then be the result of those molecules acting both locally and distantly.

NO seems to be a good candidate as a causative molecule in TIA-related headache ${ }^{24}$. Glyceryl trinitrate (GTN), a molecule that does not inducc any known action in humans but liberates NO, causes headaches in migraineurs and normal volunteers ${ }^{15}$. It is a potent vasodilator and may have a neuroprotective role as far as vessels are concerned'. However, one might speculate that vascular NO-related pain should be more diffuse, at least if NO would circulate in the blood stream. Locally released neuronal NO would tend to produce more localized pain. Accordingly, all the circulating molecules should theoretically induce diffuse pain, unless they act as a co-factor in an already locally lowered headache threshold.

Theoretically, a blood circulating headache trigger should induce pain more slowly and long-lasting that nervc-triggered pain. This is the case with NO-induced headache in migraineurs but not in normal subjects ${ }^{24}$. This may indicate that a putative circulating trigger as NO could increase a local headache tendency produced by transitory ischaemic conditions. This could explain why a circulating agent would produce a localized headache.

Let us now see this point from the innervation perspective. Trigeminal fibres are the main source of sensory innervation to supratentorial structures ${ }^{18}$. The trigeminovascular system constitutes the anatomical basis for the so-called neurogenic inflammation in cerebral arteries ${ }^{22.23}$, mediated by a series of vasoactive neuropeptides and other neurotransmitters, such as calcitonin gene-related peptide (CGRP) and substance P (SP). Both are present in trigeminal fibres ${ }^{17.29}$. CGRP is a potent vasodilating agent that can induce intense and sustained vasodilation ${ }^{4}$. It has been implicated as a transmitter responsible for restoring the vessel diameter following abnormal vasoconstriction ${ }^{10.14}$. It is also involved with the pathophysiology of migraine and cluster headache ${ }^{k}$. The predominant ipsilateral distribution of these relatively thin unmyelinated fibres explains the ipsilateral distribution of many vascular headaches. On the other hand, certain vessels, especially midline ones such as the sagittal sinus and the anterior ccrcbral arteries, may receive bilateral innervation. This could explain the bilateral distribution and the eventual contralateral predominance of headache in certain lesions affecting these vessels.

Infratentorial areas (such as the superior cerebellar arteries and the rostral basilar artery) and midline vessels may have dual - trigeminal and cervical - innervation, possibly with vessels where the two innervation systems intermingle". Cervical stimuli may induce pain referred to trigeminal territories. This may explain why some patients have frontal pain due to a vertebrobasilar disease. Cervical sensory input may interfere with trigeminal neurotransmission ${ }^{30}$. Also, It has been shown that dural and pial vessels may receive divergent axon collaterals from the same sensory trigeminal neuron. The same may occur with somatic and visceral structures within the trigeminal territory. This may explain the diffuse or poorly localized headache found in many patients. 
Pain would therefore spread through the trigeminal network surrounding pain-sensitive cerebral vessels. Impulses could trigger pain-generating nuclei in the brain stem which could explain both the frequent bilateral or contralateral distribution of headache and headaches in patients with so-called lacunar TIA. This hypothesis considers the possible role of central connections between the ischaemic focus and the brain stem ${ }^{16}$. Excitatory amino acids and other mediators could trigger pain on either side of the head through activation of brain stem structures. The nucleus raphe dorsalis and the locus cocrulcus not only project to many cortical regions but also can affect internat and external carotid circulation through parasympathetic outflow following the seventh cranial nerve and its greater superticial petrosal branch.

Still on the neuronal side, local reactions induced by nerve released agents may be of importance. Vasodilating agents and permeability promoting molccules are released from perivascular nerve endings by axon reflex-like mechanisms. This would lead to neurogenic inflammation in the dura mater and sustained pain ${ }^{23}$. Parasympathetic efferent fibres could al so be stimulated by known afferent connections with trigeminal nuclei ${ }^{16}$. As penetrating vessels receive little if any trigeminal innervation, deep gray or white matter lesions should be less often accompanied by headache. However this is doubtful in TIA and should be more adequately addressed in the future"

Cerebral vessels may be innervated not only by sensory, but also by parasympathetic fibres from the superior salivatory nucleus synapsing at the optic and sphenopalatine ganglia, and sympathetic fibres from the hypothalamus, synapsing at the superior cervical ganglion ${ }^{2 \mathrm{x}}$. Reflex mechanisms activated during TIAs may fire those three systems. Peptide release studies in ischaemiarelated headache could indicate whether these fibres are activated or not.

In the present material the pain almost always started immediately before (up to 30 minutes) or during the TIA attack. Pain onset at the end of the ischaemic symptoms was relatively rare. Close temporal patterns suggest that ischaemia and headache are pathophysiologically related and that nerves should play a role in the initiation of the pain, as circulating agents should trigger pain more slowly.

The frequent occurrence of prolonged pain in paticnts with multiplc attacks suggests that the presumed trigeminovascular system activation and subsequent antidromic neurogenic inflammation may persist even after the triggering factor is no longer present. Circulating mediators could sustain the initially neuronal-mediated headache. In this context it should be mentioned that sumatriptan and other selective $5-\mathrm{HT}_{1 \mathrm{D}}$ receptor agonists block neurogenic inflammation when administered 30 minutes after stereotactic unilateral electrical trigeminal ganglion stimulation. This suggests that peptide release from nerve endings may continue beyond the stimulation period 5 .

In ours as well as in other studies ${ }^{2.7 .20}$, the presence of migraine prior to the ischaemia does not increase susceptibility to TIA-related headaches, although a personal susceptibility to headaches should not be ruled out. Indeed, such susceptibility is suggested in patients suffering from multiple TIAs. The somewhat higher frequency of headache in female patients mirrors the sex distribution in the general population $^{23}$. This is in accordance with the data on NO-induced headache in migraineurs, cluster patients and volunteers. It seems that this molecule is not simply a headache-producer, but rather a headache trigger that respects the individual tendency to a ccrtain type of headache disorder ${ }^{24}$. The same tendency could explain why NO release during TIA would produce headache with diverse traits.

The neuroendocrine system may be in part responsible for the susceptibility to ischaemicinduced headache. The main metabolite of the antidepressant trazodone, m-chlorophenylpiperazine (m-CPP), induces migrainous headache in more than half of the individuals. Recent work suggests a close link between cortisol response and the susceptibility to headaches induced by m-CPP (both mediated by 5 -HT reccptors $)^{12}$. This indicates that there may be a gradient in the sensitivity of certain central 5-HT receptors among different subjects. We can speculate on a similar "central susceptibility" to headache following 'TIA. 
In our study of 49 patients with TIA $^{2}$, patients with a tendency for orthostatic hypotension or who were taking vasodilating drugs exhibited a threefold higher chance of having TIA-related pain. Although we could not prove it, patients with hacmodynamic stresses at the outset of the attack also tended to have more headache. Included here are patients with syncopal symptoms or with reduced cardiac output from pump failure or arrhythmias. The relative instability of the vascular bed in this group might well augment the probability of developing TIA-related headaches through as yet poorly delined neurovascular mechanisms.

Vasodilating drugs cause not only vasodilation per se but also possible changes in the geometry of perivascular axons and hence of the electrophysiologic propertics of these axons ${ }^{23}$. Postural symptoms in patients with migraine have been described ${ }^{26}$. We should keep in mind the anatomic connections between the trigeminal nucleus and the nucleus tractus solitarius ${ }^{4}$. This structure mediates blood pressure control and other autonomic functions. Postural hypotension in our patients could reflect sympathetic and parasympathetic system derangement. The classic flow autoregulation ${ }^{25}$ is consistent with the idea that vessels are extremely active in releasing vasoactive agents that could also be involved with pain, such as CGRP and NO.

None of the patients who underwent duplex-scan and intracranial Doppler examinations had a severc vascular obstruction (greater than $75 \%$ ) at the corresponding arterial territory ${ }^{2}$. This indicates that the TIA-related headache is probably not dependent upon severe structural abnormalitics of the vascular trec, but rather due to neurochemical phenomena. Edmeads suggcsted that collateral arterial vasodilation is not present either ${ }^{\text {. }}$. The absence of severe arterial obstruction and of any correlation between headache and long-term prognosis in this series strongly argues against any delctcrious effect of headache in the context of ischaemic brain insult. This has also been demonstrated following acute cerebral infarction'.

In summary, we suggest that headache and ischaemia are closely related in patients with TIA. Reflex mechanisms may induce pain far from the ischaemic territory. The roles of the trigeminovascular system, sympathetic and parasympathetic fibres, the neuroendocrine system and local mediators arc probably all intermingled in this process. Parts of this interesting puzzle are already evident, but a long way to go still remains.

\section{REFERENCES}

1. André C, Novis SAP. Clinical factors adversely affecting early outcome after brain infiarction. Arq Neuropsiquiatr 1994;52:153-160.

2. André C, Neves FF. Vincent MB. Headaches in transient ischaemic attacks. Funct Neurol 1996 (in press).

3. Astrup J, Siesjö BK, Symon L. Thresholds in cerebral ischemia: the ischemic penumbria. Stroke 1981;12:723-725.

4. Bakken IJ, Vincent MB, Sjalivilag I, White LR. Vasodilation in porcine ophthalmic altery: peptide interaction with acetyldholine ind endothelial dependence. Neurnpeptider 1995;29:69-75.

5. Buzzi MG. Bonalnini MA, Moskowitz MA. Neurogenic model of migraine. Cephalallgiil 1995:15:277-280.

6. Dalkarat T, Moskowitz MA. The complex role of nitric oxide in the puthophysiology of focil cerebral ischemiit. Bruin Pathol 1994:4:49-57.

7. Edmeatls. I. The headlaches of ischemic cerebroviscular disease. Headiche 1979;19:345-349.

8. Edvinsson L. Goadsby P. Neuropeptides in migraine and cluster headache. Cephalalgia 1994:14:320-327.

9. Edvinsson L, Hara H. Uddmain R. Retrograde tracing of nerve fibses to the rat middle cerebral artery with true bluc: colocillization with different peptides. J Cereb Blond Flow Metib 1989;9:212-218.

10. Edvinsson L, Juul R. Jansen I. Perivascular neuropeptides (NPY, VIP, CGRP and SP) in human brain vessels after subarachnoid baemorrhage. Actii Neurol Scind 1994;90:324-327.

11. Ferro JM. Costa l. Melo TP et all. Heidache associated with tansient ischemic attacks. Headache 1995;35:544-548.

12. Gordon ML, Lipton RB, Brown S-L, van Pralig HM. The neuroendocrine challenge paradigm in heudache rescirch. Cephalalgial 1995:15:292-296.

13. Gorelick PB. The secondary headaches: ischemic stroke and intracranjal hematoma. In Olesen I, Tfelt-Hansen P, Welch KMA (eds). The Headiaches. New York: Raven Press, 1993-639-645.

14. Headiache Classification Committee of the International Headache Society. Classificition ind diagnostic criteria for headache disorders, crinial neuralgiais and tacial pain. Cephalulgia 1988;8 (Supp1 7): 1-96.

15. Iversen HK. Olesen J. Tielt-Hansen P. Intravenous nitroglicerin als an experimentill model of valscular headdache: basic characteristics. Pain 1989:38:17-24.

16. Lince JW. Current concepts of migriune pathogenesis. Neurology 1993; 43(Suppl.3):S II-S|5. 
17. Lee Y. Kitwai T, Shiosaka S et al. Coexistence of calcitonin gene-related peptide in single cells of the trigeıninal ganglion of the ral: immunohistochemical anillysis. Brain Res 1985;330:194-196.

18. Malybetg MR, Zervas NT; Moskowitz MA. Trigeminal projections to supratentorial pial and dutal blood vessels in cats demonstrated by horseradish peroxidase histochemistry. J Comp Neurol 1984;223:46-56.

19. McCullok' I, Uddman R, Kingman TA, Edvinsson L. Calcitonin gene-related peptide: functional role in cerebrovascular regulation. Proc Natl Acad Sci USA 1986;83:5731-5735.

20. Medinat JL. Diamond S, Rubino FA. Headaches in patients with transient ischemic attacks. Headache 1975;15:194-197.

21. Mitsias P. Ramadan NM. Headache in ischemic cerebrovascular disease. Part I: Clinical features. Cephalalgia 1992;12:269-274

22. Moskowitz MA. The neurobiology of vascular head pain. Ann Neurol 1984;16:157-168.

23. Moskowitz MA. Neurogenic inflammation in the pathophysiology and treatment of migraine. Neurology 1993:43(Suppl3):S16-S?0.

24. Olesen J, Thomsen LL, Lassen LH, Olesen IJ. The nitric oxide hypothesis of migraine and other vascular headaches. Cephalalgia 1995:15:94-100.

25. Pauson OB, Standgatad S, Edvinsson L. Cerebral autoregulation. Cerebrovasc Brain Metab Rey 1990:2:161-192.

26. Raskin NH, Knittle SC. Ice crean headache and orthostatic symptoms in patients with migraine. Healdache 1976;1 6:222-225.

27. Riy BS. Wolff HG. Experimental studies on headache: pain sensitive structures of the head and their significance in bealdache. Arch Surg 1940:41:813-856.

28. Uddman R. Edvinsson L. Neuropeptides in the cerebral circulation. Cerebrovasc Brain Metab Rev 1989:1:230-252.

29. Uddman R. Edvinsson L. Ekman R, McCulloch J, Kingman TA. Innervation of the feline cerebral vasculature by nerve fibres containing calcitonin gene-related peptide: trigeminal origin and co-existance with substance P. Neurosci Lett I985;62:13!-136.

30. Vincent MB. Ekmian R. Edvinsson L. Sand T, Sjaastidd O. Reduction of ealcitonin gene related peplide in jugular blood following elcctrical stimulation of rat greater occipital nerve. Cephalalgia 1992;12:275-279. 